\title{
Optimal energy management of a grid-connected multiple energy carrier micro-grid
}

\author{
Seyed Masoud Moghaddas-Tafreshi ${ }^{a,}{ }^{*}$, Soheil Mohseni ${ }^{a}$, Ehsan Karami ${ }^{a}$, Scott Kelly ${ }^{b}$ \\ ${ }^{a}$ Department of Electrical Engineering, Faculty of Engineering, University of Guilan, Rasht, Iran \\ ${ }^{b}$ Institute for Sustainable Futures, University of Technology Sydney, Sydney, NSW, Australia \\ * Corresponding author, Email: tafreshi@guilan.ac.ir
}

\begin{abstract}
This paper presents a novel modeling approach to optimize the electrical and thermal energy management of a multiple energy carrier micro-grid with the aim of minimizing the operation cost such that system constraints are satisfied. The proposed micro-grid includes a micro-turbine, a fuel cell, a reject burning (RB) power plant, a wind turbine generator system, a boiler, an anaerobic reactor-reformer system, an inverter, a rectifier, and some energy storage units. The model uses day-ahead forecasting ( 24 hours) to estimate the electrical and thermal loads on a micro-grid network. A day-ahead forecast is also used to estimate electricity generation from wind turbines. Due to the uncertainty associated with day-ahead forecasts a Monte Carlo simulation is used to estimate thermal loads, electrical loads, and wind power generation. Also, a real time pricing (RTP) demand response program is used to shift non-vital loads. The operating cost of the micro-grid is minimized through the particle swarm optimization algorithm. The simulation results demonstrate the proposed method is capable of minimizing the operating cost of the micro-grid whilst adhering to constraints on pollution and a real-time pricing demand response program. In addition, the results obtained by applying the proposed method are analyzed and validated through scenario testing.
\end{abstract}

Keywords: Optimal energy management, Micro-grid, Multiple energy carrier, Renewable energy sources

\section{Introduction}

Distributed generation systems that are located close to where electricity is finally consumed have been proposed as one solution to overcome many of the problems associated with large centralized fossil-based power plants (e.g. high power losses, high emissions, expensive capital infrastructure etc.) [1-4]. As the penetration of renewable energy sources (RES) increases, the uncertainty associated with renewable resources - like solar and wind energy - will have an increasing impact on distributed energy networks [5-8]. One solution for dealing with the intermittent nature of RES is the concept of a micro-grid that facilitates the use of demand response programs $[9,10]$. Micro-grids are discrete, small power grids that provide a platform for the integration of distributed energy resources and loads that can be operated in both grid-connected and islanded modes with the potential for increased utilization of RES [11,12]. The multiple energy carrier micro-grid is referred to as an interconnected energy carrier network that establishes a coupling of power flows for the optimal operation of power system infrastructure for sustainable development.

In this paper, we aim to calculate the optimal operation strategy for a grid-connected multiple energy carrier microgrid to schedule the components of the system while satisfying the electrical and thermal demands of consumers. The micro-grid is equipped with a micro-turbine (MT), a fuel cell (FC), a reject burning (RB) power plant, a wind turbine (WT) generator system, a boiler, an anaerobic reactor-reformer system, an inverter, a rectifier, and some energy storage units. The micro-grid network has bilateral power exchange with the upstream power grid. In this paper, we have implemented a multi-agent modeling framework to calculate the optimal solution for the day-ahead operation of the micro-grid. The proposed multi-agent system (MAS) allows for the exchange of information between different levels of the system, which increases the reliability of the system and simplifies the complexity of the modeling task.

This paper is organized as follows: In section 2, we provide a review of the state-of-the art in modelling energy demand dispatch for a micro-grid. In section 3, the structure of the proposed multiple energy carrier micro-grid is presented. Section 4 describes the MAS used for the optimal operation of the proposed micro-grid along with the description of components belonging to each agent as well as modeling of the demand-side management program and uncertain parameters. Section 5 presents the simulation results of the multi-agent architecture used for the optimal operation of the proposed micro-grid. Finally, the conclusion of this study is presented in section 6 . 


\section{Review of relevant literature}

Given the multi-objective nature of such problems, several researchers have started to develop optimization models to minimize overall costs and minimize total emissions to the environment. Optimal operation of a micro-grid is necessary as this ensures the cost-effective power supply while satisfying the preferences of consumers. The optimal operation of the micro-grid is a complicated issue since it needs to consider both the constraints on the system whilst minimizing cost. In a single energy carrier system, the optimal operation is less complicated as it does not need to consider the interdependency between various energy carriers. Various studies have been conducted on the optimal operation of single energy carrier micro-grids using a range of different computational optimization techniques to realize sustainable development goals [13-16].

Louie [17] considers the optimal operation of hybrid solar/wind micro-grids. Utilizing 14 months of data, Louie [17] has performed statistical and time-series analyses and has described an optimal operation methodology using various strategies under a range of operational conditions. Louie [17] demonstrates that his proposed optimal solution achieves an average efficiency gain of $67 \%$ justifying its application to hybrid solar/wind micro-grids. Zhang et al. [18] propose a predictive control based optimal operation approach for a residential micro-grid. The benefit of this approach is that it considers the uncertainty associated with wind speed. The authors have optimized a mixed integer linear programming problem at each decision point, and have integrated it into a predictive control model to reduce the negative impacts of forecast errors. Also, they have performed a sensitivity analysis to discuss the impacts of energy storage units on the operation of the micro-grid and have demonstrated that their method is economical and flexible. A probabilistic analysis of optimal power scheduling considering the economic aspects in micro-grids environment is discussed by Nikmehr et al. [19]. The authors' solution implements an imperialist competitive algorithm and compares their results with a typical Monte Carlo simulation confirming the superiority of their proposed method. The simultaneous scheduling of electric vehicles and responsive loads within a micro-grid environment is considered by Rabiee et al. [20] which aims to minimize both operational costs and emissions. In this paper the authors develop a two-stage model to determine the operation cost of the micro-grid. In the first stage, the generation and reserve power costs are minimized whilst in the second stage, the costs associated with unit scheduling is minimized due to the variable nature of solar and wind generation. Based on their results, the authors conclude that the incorporation of electric vehicles and responsive loads can be managed to achieve optimal operation of a micro-grid, resulting in decreased operational costs and lower emissions. These benefits therefore compensate for the uncertainties associated with wind and solar generation.

A methodology which incorporates both the size of the resource and the strategy by which it is operated is presented by Zhao et al. [21] for Dongfushan Island in China. The authors use a genetic algorithm-based method to solve the optimization problem such that it minimizes the life-cycle cost, maximizes the renewable energy source penetration, and minimizes pollutant emissions. A probabilistic energy management system is proposed by Mohammadi et al. [22] that aims at optimizing the operation of a micro-grid based on a point estimate method that considers the uncertainty associated with different variables. For example to represent the uncertainty associated with solar generation, wind generation, and load demand the authors use the Beta, Weibull, and normal distributions, respectively. They also employ an adaptive modified firefly algorithm to achieve an optimal scheduling of a typical micro-grid with regard to cost minimization. In order to determine the optimal operation of a renewable micro-grid across a $24 \mathrm{~h}$ time horizon, Baziar et al. [23] incorporate several types of RES like wind turbines, photovoltaic arrays, micro-turbines and fuel cells as well as energy storage devices such as battery packs under two different scenarios. In the first scenario, all distributed generators are assumed to be active, while in the second scenario, the distributed generators can switch between being either ON or OFF providing increased flexibility over the operation of the grid. By introducing a probabilistic framework based on the two point estimate method, the authors have modeled the uncertainty associated with load forecast error, the utility of bid changes, and the output power variations introduced to the micro-grid from wind and solar generation. Baziar et al. [23] have claimed that their self-adaptive modification method, based on the particle swarm optimization (PSO) algorithm, has overcome the deficiencies of the traditional optimization algorithms by decreasing the convergence time and extending the solution space.

The impact of demand response programs consisting of various types of RES is investigated by Nikmehr et al. [24] to optimize day-ahead scheduling on a networked micro-grid. In this paper, the authors investigate two demand response programs based on Time of Use (ToU) and Real Time Pricing (RTP). The model implements the PSO algorithm to optimize the micro-grid under the condition of uncertain distributed generation and loads. Based on the results, the authors conclude that the real-time reaction of consumers to cost fluctuations has the potential to lead to significant cost reductions for both power producers and electricity users resulting in a flatter demand curve. Niknam et al. [25] implement a stochastic model for the optimal energy management of a micro-grid with the dual goals of cost and emission minimization, while simultaneously incorporating the uncertainty of load demand, market prices, and the output power generation of wind and solar. In order to solve this model the authors implement a multi-objective teaching-learning based optimization algorithm to yield the best expected Pareto optimal front. Moreover, they offer a self-adaptive probabilistic modification strategy to improve the performance of their algorithm. A stochastic riskconstrained programming model is proposed by Dolatabadi et al. [26] to optimize the performance of a smart energy 
hub over the short term to minimize the operating costs. In order to predict the wind speed and load demand, the authors use a probability density function. The model also incorporates demand response programs to handle the uncertainties associated with the predicted wind power generation and load demand. By optimizing the operational costs through a two-stage stochastic mixed-integer linear programming model, the authors successfully demonstrate it is possible to reduce operational costs if consumers participate in demand response programs.

In comparison with a single energy carrier micro-grid, a multiple energy carrier micro-grid is a more complex system since it needs to optimize output from various energy carriers with each having their own unique characteristics. Few researchers have addressed the problem of optimal operation of multiple energy carrier micro-grids. One example is the optimization model developed for the operation of the University of Genoa Smart Polygeneration Micro-grid [27]. In this multiple energy carrier micro-grid there are two micro-turbines, two boilers, a thermal storage unit, an absorption chiller, three concentrated solar power units, an electrical storage system, a roof-mounted photovoltaic field, and two recharging stations for electric vehicles. The authors conclude that multiple energy carrier micro-grids can effectively determine economic and environmental benefits only if they are operated following an optimization strategy. An autonomous multiple energy carrier micro-grid is developed by Karavas et al. [28] in order to cover the complete utility service requirements for a remote area which includes electricity, space heating and cooling, potable water through desalination, and hydrogen as the fuel for transportation. The authors show the optimal operation of this decentralized energy management system can be achieved through a MAS that allows for the control of each unit of the micro-grid independently. By comparing their results with a case study that uses a centralized energy management system, the authors conclude that the decentralized energy management system presents improvements in operational and financial terms for the implementation and operation of an autonomous multiple energy carrier micro-grid. Related to this work La Scala et al. [29] implement an optimization framework and a hierarchical control architecture for a system consisting of multiple energy carriers. The framework they develop is based on the energy hub concept with a multi-objective goal attainment method that meets the loads, minimizes the energy costs, and assures a reliable operation of the multicarrier energy network over a $12 \mathrm{~h}$ time horizon. The coordinated operation and optimal scheduling strategies for a multiple energy carrier system at the whole micro energy grid level are studied by Ma et al. [30]. The system includes power, heating, and cooling sub-systems. The model also integrates RES, combined cooling heating and power units, and energy storage devices. In order to minimize the daily operation cost, the authors formulate a day-ahead dynamic optimal operation model as a mixed integer linear programming optimization problem whilst simultaneously considering a demand response strategy. Based on the numerical simulation results, the authors have claimed that their proposed methodology is universal and effective over the entire energy dispatching horizon.

Optimal operation strategies are inherently complex due to the variable nature of RES, the fluctuations in demand load and the uncertainty of market prices. Nevertheless, the above review of the state-of-the-art has shown that the optimal operation of a micro-grid energy system can achieve significant reductions in both cost and pollution. The review highlights the need for such models to consider the uncertainties associated with micro-scale renewable generation on the supply side and of power consumption loads on the demand side. In addition, several of the more advanced models that were reviewed provide the ability to perform demand-side management; export renewable energy back into to the upstream network; incorporate the effects of real-time market prices and optimize across different types of utility service requirements (e.g. heating, cooling, electricity, water and transport). Although some research has started to solve the problem of optimally operating multiple energy carrier micro-grids, most of this research has failed to take into account the effect of demand response programs and the uncertainty associated with the output power from renewable generation including both electrical and thermal loads. Handling the uncertain parameters of a multiple energy carrier micro-grid and performing an appropriate demand response program is essential if efficient, reliable, and affordable delivery of electricity and heat to consumers is going to be achieved whilst simultaneously contributing to the goals of sustainable development. It is worth noting that the reason for selecting day-ahead operation in this paper is that it is assumed that the model uses day-ahead forecasting to estimate electrical loads, thermal loads, and wind power generation.

\section{Micro-grid structure}

The micro-grid considered in this paper includes a micro-turbine, a fuel cell, an RB power plant, a wind turbine, a boiler, an anaerobic reactor-reformer system, an inverter, a rectifier, an electrical storage system (ESS), a thermal storage system (ThSS), and a hydrogen tank (HT). Also, the micro-grid is connected to the upstream power grid with bilateral power exchange. 


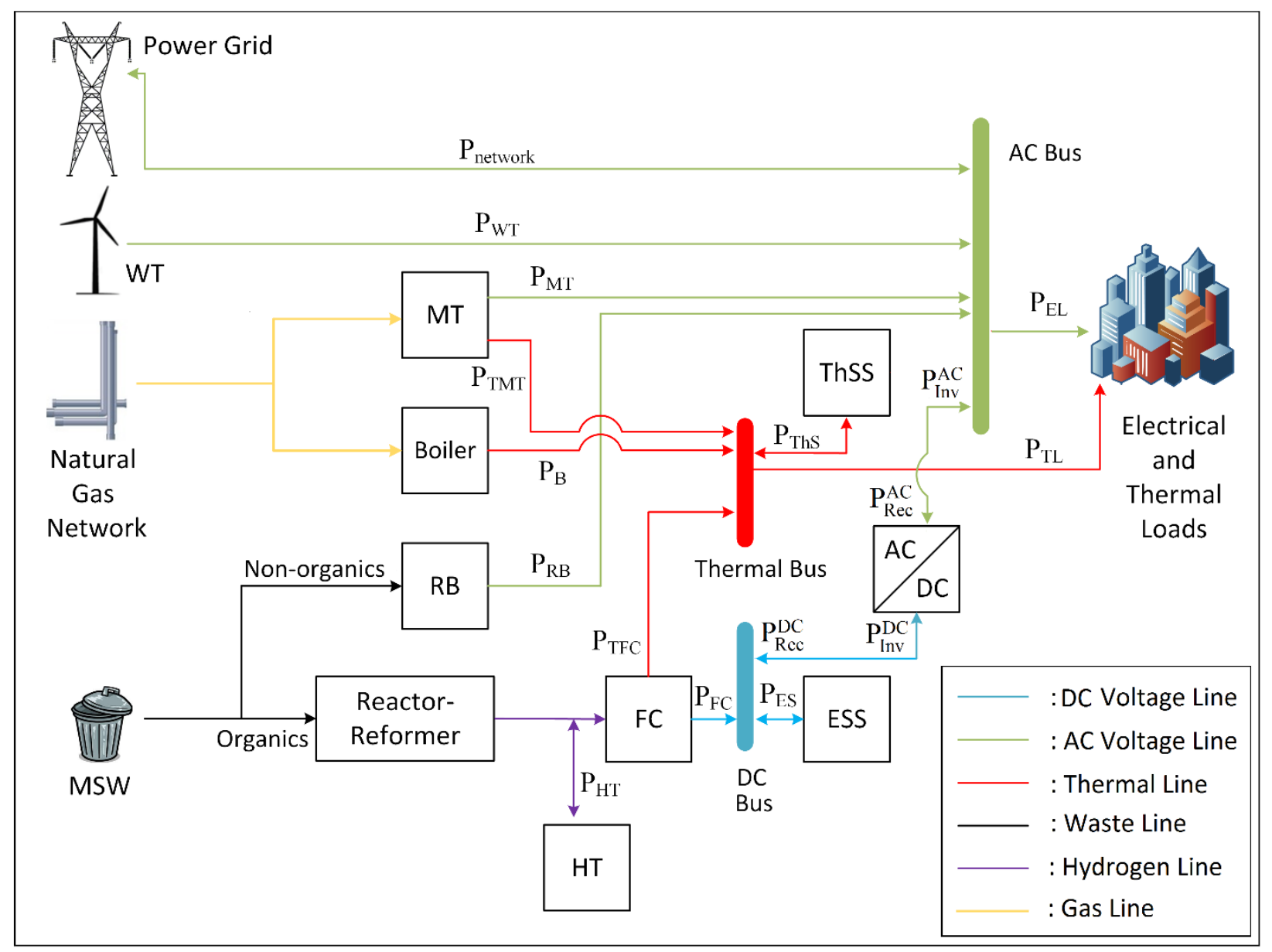

Fig. 1. The structure of the proposed grid-connected multiple energy carrier micro-grid.

Power flow diagram of the proposed micro-grid is shown in Fig. 1. According to this schematic diagram, municipal solid waste (MSW) is separated by the one-way sorting and separation system which involves the two categories of MSW, organics and non-organics. The organic fraction of the MSW is fed to the anaerobic reactor. The methane obtained from the anaerobic reactor is used by the reformer to produce hydrogen. The hydrogen produced by the reformer is used by the fuel cell to produce electricity and heat. A hydrogen tank is used to store any surplus hydrogen that is produced by the anaerobic reactor-reformer system and also as a resource to compensate for any lack of hydrogen. The non-organic fraction of the MSW is burned in the RB power plant to produce electricity.

Another source of electrical and thermal energy generation is the micro-turbine that receives the natural gas as input and produces both electrical and thermal energy. The heat generated by the fuel cell and micro-turbine is used to supply the thermal loads. Also, a thermal storage system is considered to store the surplus thermal energy produced by the combined heat and power units and compensate for any lack of thermal energy when necessary. If the total thermal energy generated by the fuel cell, micro-turbine, and thermal storage system is insufficient for meeting the thermal load, then a boiler that is a natural gas-fired burner compensates and produces the required thermal energy.

The renewable power generation system includes wind turbine generators that produce electrical energy when there is sufficient wind speed. The micro-grid has bilateral electrical power exchange with the upstream power grid and the required electrical load is separated into both vital and non-vital loads. Therefore, with this system it is possible to shift a percentage of the total non-vital load from peak periods to off-peak periods. It is worth noting that at each hour, $15 \%$ of the electrical load is considered to be non-vital.

\section{Proposed multi-agent energy management system}

A MAS is a loosely coupled network of software agents that interact to solve problems that are beyond the individual capacities or knowledge of each individual agent. A MAS can therefore be defined as a combination of several agents 
working in collaboration performing assigned tasks to achieve the overall goal(s) of the system [31]. In fact, there is no general formula for a MAS and it simplifies the complex modeling tasks by defining different agents with different rules and enabling information to be exchanged between the agents within the system.

The considered MAS for optimal operation of the proposed micro-grid has eight agents, namely, upstream network agent, micro-grid agent, thermal agent, hydrogen agent, RB unit agent, renewable agent, storage agent, and load aggregator agent which are organized in three layers. These three layers are presented in Fig. 2. All the agents associated with the generation or consumption of electricity/hydrogen/heat belong to the field layer. In the micro-grid operator layer, the coordination of generation and consumption of the electrical and thermal loads is estimated. The micro-grid agent belongs to this layer in which the micro-grid operator aims for the optimal operation of the different components of the proposed micro-grid, under both equality and inequality constraints. The upstream network layer includes the natural gas network and the power grid. The upstream network agent belongs to this layer and serves as a redundant source of energy that compensates for the shortage of any energy production.

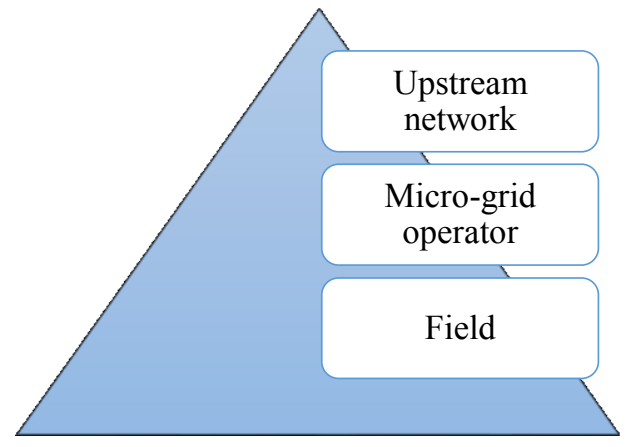

Fig. 2. The architecture of the MAS.

In the following subsections, the responsibilities of each agent are described, the mathematical modeling of the microgrid components is presented, the objective function and constraints of the optimization problem are formulated, and the process of data exchange between the agents is explained. Also, the amount of $\mathrm{CO} 2, \mathrm{SO}_{2}$, and $\mathrm{NO}_{\mathrm{x}}$ emissions produced by operating the micro-turbine, fuel cell, RB power plant, and boiler are modeled and an emissions constraint is met while optimally scheduling the components of the micro-grid.

\subsection{Modeling of agents}

\subsubsection{Upstream network agent}

This agent is responsible for announcing the hourly price of purchasing and selling the electricity, the price of purchasing the natural gas, and the energy exchange restrictions to the micro-grid agent.

\subsubsection{Micro-grid agent}

This agent is responsible for announcing the hourly price of purchasing and selling the electricity and the price of purchasing the natural gas announced by the upstream network to the field layer agents, requesting the thermal agent, hydrogen agent, RB unit agent, and storage agent to announce their status, requesting the renewable agent to announce its generated power considering the uncertainty associated with wind power generation forecasts, requesting the load aggregator agent to announce the amount of electrical and thermal loads considering the uncertainty associated with their forecasted values as well as the amount of available non-vital electrical loads, optimal scheduling of the microgrid components, and satisfying the constraints imposed by the upstream network and field layer agents while minimizing the operational cost of the micro-grid taking into account an emissions constraint.

As stated earlier, the proposed micro-grid has a bilateral electrical power exchange with the upstream power grid. The cost of power exchange with the upstream grid is calculated by the following equation [32]:

$$
\operatorname{cost}_{\text {network }}(t)= \pm P_{\text {network }}(t) \pi_{\text {network }}(t) \Delta t,
$$

where $P_{\text {network }}(t)$ is the micro-grid's exchanged power with the upstream power grid at time step $t$ and $\pi_{\text {network }}(t)$ is the price of power exchange per $\mathrm{kWh}$ at time step $t$. It is worth noting that a positive value of $P_{\text {network }}(t)$ represents a purchased power from the upstream power grid and a negative value represents any sold power to the upstream power grid. The variable $\Delta t$ is the length of each time step and is taken to be 1 hour in this study.

The power exchange with the upstream power grid at time step $t$ is subject to the following constraints: 


$$
P_{\text {network,min }} \leq P_{\text {network }}(t) \leq P_{\text {network,max }}
$$

where $P_{\text {network,min }}$ and $P_{\text {network,max }}$ are the minimum and maximum allowable power exchange of the micro-grid with the upstream power grid, respectively. The minimum and maximum values could represent either economic or practical limitations on the system. For example, the minimum value could represent the minimally economically viable power exchange with the grid, while the maximum could represent a physical upper constraint on the size of the electric cable connecting the micro-grid with the upstream grid.

Also, the electrical and thermal power balance equations should be considered in the optimization problem. The microgrid agent checks the following equations at each time step $t$ and operates the system such that these conditions are met. The electrical power balance equation can be defined by the following equation:

$$
P_{M T}(t)+P_{R B}(t)+P_{W T}(t)+P_{I n v}^{A C}(t)-P_{R e c}^{A C}(t) \pm P_{\text {network }}(t)=P_{E L}(t),
$$

where $P_{M T}(t), P_{R B}(t)$, and $P_{W T}(t)$ represent the electrical output power of the micro-turbine, RB power plant, and wind turbine generator system at time step $t$, respectively. Furthermore, $P_{I n v}^{A C}(t), P_{R e c}^{A C}(t)$, and $P_{E L}(t)$ represent the AC power of the inverter, the AC power of the rectifier, and the electrical power demand on the micro-grid at time step $t$, respectively.

The AC power of the inverter and rectifier can be calculated according to the following equations:

$$
\begin{gathered}
P_{I n v}^{A C}(t)=P_{I n v}^{D C}(t) \eta_{I n v^{\prime}} \\
P_{R e c}^{A C}(t)=P_{R e c}^{D C}(t) / \eta_{\text {Rec }},
\end{gathered}
$$

where $P_{I n v}^{D C}(t)$ and $P_{R e c}^{D C}(t)$ represent the DC power of the inverter and rectifier at time step $t$, respectively. Moreover, $\eta_{I n v}$ and $\eta_{\text {Rec }}$ are the efficiencies of the inverter and rectifier, respectively.

The thermal power balance equation can be defined by the following equation:

$$
P_{T M T}(t)+P_{T F C}(t)+P_{B}(t) \pm P_{T h S}(t)=P_{T L}(t),
$$

where $P_{T M T}(t), P_{T F C}(t)$, and $P_{B}(t)$ represent the thermal output power of the micro-turbine, fuel cell, and boiler at time step $t$, respectively. Furthermore, $P_{T h S}(t)$ and $P_{T L}(t)$ represent the charging/discharging output of the thermal storage system and the thermal power demand of the micro-grid at time step $t$, respectively. It is worth noting that a positive value of $P_{T h S}(t)$ represents the discharging mode of the thermal storage system and a negative value represents the charging mode.

The amount of air pollutant emissions produced by operating the proposed micro-grid in $\mathrm{kg} / \mathrm{kWh}$ is equal to the sum of emissions produced by operating the micro-turbine, fuel cell, RB power plant, and boiler over the scheduling horizon ( 24 hours) and can be calculated according to the following equation:

$$
\text { Emission }=\sum_{t=1}^{24} \text { emission }_{M T}(t)+\text { emission }_{F C}(t)+\text { emission }_{R B}(t)+\text { emission }_{B}(t) .
$$

The optimal operation of the micro-grid is subject to the following constraint:

$$
\frac{\text { Emission }}{\sum_{t=1}^{24} P_{E L}(t)} \leq \text { Emission }_{\max }
$$

where Emission $_{\max }$ is the maximum allowable emissions and is a constant equal to $0.664 \mathrm{~kg} / \mathrm{kWh}$.

In this study, the objective function is the total cost of operating the micro-grid including the fuel cost, operation and maintenance (O\&M) cost, and startup cost of the components that participate in the considered optimal scheduling problem in addition to the cost of power exchanges with the upstream power grid that can be defined as

$$
\begin{aligned}
f=\sum_{t=1}^{24} \operatorname{cost}_{f u e l, M T}(t)+\operatorname{cost}_{O \& M, M T}(t)+\cos _{S U, M T}(t)+\operatorname{cost}_{f u e l, F C}(t) \\
\\
+\operatorname{cost}_{O \& M, F C}(t)+\cos _{S U, F C}(t)+\operatorname{cost}_{f u e l, R B}(t)+\operatorname{cost}_{O \& M, R B}(t)+\operatorname{cost}_{S U, R B}(t) \\
+\operatorname{cost}_{O \& M, W T}(t)+\operatorname{cost}_{O \& M, E S}(t)+\operatorname{cost}_{O \& M, T h S}(t) \\
+\operatorname{cost}_{O \& M, H T}(t)+\operatorname{cost}_{\text {network }}(t) .
\end{aligned}
$$


It is worth noting that $P_{M T}, P_{F C}, P_{R B}, P_{E S}$, and $P_{\text {network }}$ are considered as decision variables. Therefore, at each time step $t$, we will have five decision variables and $120(5 \times 24)$ decision variables for the operating horizon.

Minimizing the objective function is achieved by using the PSO algorithm which was first introduced by Kennedy and Eberhart in 1995 [33]. Compared to alternative methods, the PSO is powerful because instead of using a 'survival of fittest' approach, the members of the PSO population interact and influence each other [34].

\subsubsection{Thermal agent}

This agent is responsible for announcing the range of power that can be generated by the micro-turbine and boiler subject to operational constraints, fuel costs, O\&M costs, startup costs, and allowable emissions. The thermal agent is also responsible for operating the micro-turbine and boiler based on the received commands from the micro-grid agent.

The electrical output power of the micro-turbine at time step $t$ can be calculated according to the following equation:

$$
P_{M T}(t)=\frac{\eta_{M T} H H V_{g a s} G_{M T}(t)}{\Delta t},
$$

where $\eta_{M T}$ is the efficiency of the micro-turbine, $H H V_{\text {gas }}$ is a constant that represents the higher heating value of natural gas, and $G_{M T}(t)$ is the fuel consumption of the micro-turbine at time step $t$. It is worth noting that the higher heating value of natural gas is equal to $50.67 \mathrm{MJ} / \mathrm{kg}$ [35]. The thermal output power of the micro-turbine at time step $t$ can be calculated by the following equation:

$$
P_{T M T}(t)=K_{\text {Thermal }, M T} P_{M T}(t),
$$

where $K_{\text {Thermal,MT }}$ is a constant coefficient that relates the electrical output power of the micro-turbine to its thermal output power. Furthermore, the thermal output power of the boiler at time step $t$ can be calculated by the following equation:

$$
P_{B}(t)=\frac{\eta_{B} H H V_{g a s} G_{B}(t)}{\Delta t},
$$

where $\eta_{B}$ and $G_{B}(t)$ are the efficiency and fuel consumption of the boiler at time step $t$, respectively.

The fuel cost of the micro-turbine plant at time step $t$ can be calculated by the following equation:

$$
\operatorname{cost}_{f u e l, M T}(t)=P_{M T}(t) B_{g a s} \Delta t,
$$

where $B_{\text {gas }}$ is the cost rate of natural gas. The O\&M cost of the micro-turbine at time step $t$ can be calculated according to the following equation:

$$
\operatorname{cost}_{O \& M, M T}(t)=u_{M T}(t) P_{M T}(t) B_{O \& M, M T} \Delta t,
$$

where $u_{M T}(t)$ is a binary variable, being equal to 1 during the operation of the micro-turbine and 0 during other time steps, and $B_{O \& M, M T}$ is the O\&M cost rate of the micro-turbine.

The startup cost of the micro-turbine at time step $t$ can be defined by the following equation:

$$
\operatorname{cost}_{S U, M T}(t)=S_{M T}\left|u_{M T}(t)-u_{M T}(t-1)\right| \Delta t,
$$

where $S_{M T}$ is the startup cost rate of the micro-turbine. The amount of air pollutants generated by the micro-turbine at time step $t$ can be calculated by the following equation:

$$
\text { emission }_{M T}(t)=u_{M T}(t) P_{M T}(t) E_{M T} \Delta t
$$

where $E_{M T}$ is the emission rate of the micro-turbine. A similar equation estimates the amount of emissions produced by the boiler where the $M T$ indices in Eq. (16) should be substituted by the $B$ indices to represent the emissions produced by the boiler.

The operation of the micro-turbine and boiler at time step $t$ is subject to the following constraints:

$$
\begin{gathered}
P_{M T, \min } \leq P_{M T}(t) \leq P_{M T, \max }, \\
P_{T M T, \min } \leq P_{T M T}(t) \leq P_{T M T, \max }, \\
P_{B, \min } \leq P_{B}(t) \leq P_{B, \max },
\end{gathered}
$$


where $P_{M T, \min }, P_{M T, \max }, P_{T M T, \min }$, and $P_{T M T, \max }$ represent the minimum and maximum allowable electrical and thermal output power of the micro-turbine, respectively. Also, $P_{B, \min }$ and $P_{B, \max }$ are the minimum and maximum allowable output power of the boiler, respectively.

\subsubsection{Hydrogen agent}

This agent is responsible for announcing the range of power that can be generated by the fuel cell subject to operational constraints (e.g. the minimum and maximum storage capacities of the tank, the initial hydrogen state of the tank etc.), fuel cost of the fuel cell, O\&M costs of the fuel cell and hydrogen tank, startup cost of the fuel cell, and allowable emissions. The hydrogen agent is also responsible for operating the fuel cell and hydrogen tank based on the received commands from the micro-grid agent.

The electrical output power of the fuel cell at time step $t$ can be calculated according to the following equation:

$$
P_{F C}(t)=\frac{\eta_{F C} \eta_{r e f} H H V_{\text {methane }} G_{F C}(t)}{\Delta t}
$$

where $\eta_{F C}$ is the efficiency of the fuel cell, $\eta_{r e f}$ is the efficiency of the anaerobic reactor-reformer system, $H H V_{\text {methane }}$ is the higher heating value of the methane and is a constant equal to $54.8 \mathrm{MJ} / \mathrm{kg}[36]$. The variable $G_{F C}(t)$ is the fuel consumption of the fuel cell at time step $t$. The thermal output power of the fuel cell at time step $t$ can be calculated by the following equation:

$$
P_{T F C}(t)=K_{\text {Thermal }, F C} P_{F C}(t),
$$

where $K_{\text {Thermal,FC }}$ is a constant coefficient that relates the electrical output power of the fuel cell to its thermal output power.

The fuel cost of the fuel cell at time step $t$ can be calculated by the following equation:

$$
\operatorname{cost}_{\text {fuel, }, F C}(t)=P_{F C}(t) B_{f u e l, F C} \Delta t,
$$

where $B_{f u e l, F C}$ is the fuel cost rate of the fuel cell that can be calculated by the following equation:

$$
B_{f u e l, F C}=\frac{B_{\text {methane }}}{\eta_{F C} \eta_{\text {ref }}}
$$

where $B_{\text {methane }}$ is the cost rate of methane. The O\&M cost of the fuel cell at time step $t$ can be calculated according to the following equation:

$$
\text { cost }_{O \& M, F C}(t)=u_{F C}(t) P_{F C}(t) B_{O \& M, F C} \Delta t,
$$

where $u_{F C}(t)$ is a binary variable, being equal to 1 during the operation of the fuel cell and 0 during other time steps, and $B_{O \& M, F C}$ is the O\&M cost rate of the fuel cell.

The startup cost of the FC at time step $t$ can be defined by the following equation:

$$
\operatorname{cost}_{S U, F C}(t)=S_{F C}\left|u_{F C}(t)-u_{F C}(t-1)\right| \Delta t,
$$

where $S_{F C}$ is the startup cost rate of the fuel cell. The amount of air pollutants generated by the fuel cell at time step $t$ can be calculated by the following equation:

$$
\text { emission }_{F C}(t)=u_{F C}(t) P_{F C}(t) E_{F C} \Delta t,
$$

where $E_{F C}$ is the emission rate of the fuel cell. The operation of the fuel cell at time step $t$ is subject to the following constraints:

$$
\begin{gathered}
P_{F C, \text { min }} \leq P_{F C}(t) \leq P_{F C, \text { max }}, \\
P_{T F C, \text { min }} \leq P_{T F C}(t) \leq P_{T F C, \text { max }},
\end{gathered}
$$

where $P_{F C, \text { min }}, P_{F C, \text { max }}, P_{T F C, \text { min }}$, and $P_{T F C, \text { max }}$ represent the minimum and maximum allowable electrical and thermal output power of the fuel cell, respectively.

The amount of hydrogen stored in the tank at time step $t$ can be calculated by the following equation: 


$$
V_{\text {tank }}(t)=V_{\text {tank }}(t-1)+\Delta V_{\text {tank }}(t),
$$

where $\Delta V_{\text {tank }}(t)$ is defined as

$$
\Delta V_{\text {tank }}(t)= \pm \frac{E_{H_{2}}(t) \rho_{H_{2}}}{H H V_{H_{2}}},
$$

where $E_{H_{2}}(t)$ is the charging/discharging output energy of the hydrogen tank at time step $t, \rho_{\mathrm{H}_{2}}$ is the density of the hydrogen and is a constant that is equal to $0.085 \mathrm{~g} / \mathrm{L}$, and $H H V_{\mathrm{H}_{2}}$ is the higher heating value of hydrogen that is a constant equal to $142 \mathrm{MJ} / \mathrm{kg}$ [36]. It is worth noting that a positive value of $\Delta V_{\text {tank }}(t)$ represents the charging mode of the tank and a negative value represents the discharging mode.

The O\&M cost of the RB power plant at time step $t$ can be calculated according to the following equation:

$$
\operatorname{cost}_{O \& M, H T}(t)=u_{H T}(t) P_{H T}(t) B_{O \& M, H T} \Delta t,
$$

where $u_{H T}(t)$ is a binary variable, being equal to 1 during the charging/discharging of the tank and 0 during other time steps, $P_{H T}(t)$ is the charging/discharging output power of the hydrogen tank at time step $t$, and $B_{O \& M, H T}$ is the O\&M cost rate of the tank.

The operation of the hydrogen tank at time step $t$ is subject to the following constraints:

$$
V_{\text {tank,min }} \leq V_{\text {tank }}(t) \leq V_{\text {tank,max }},
$$

where $V_{\text {tank,min }}$ and $V_{\text {tank,max }}$ are the minimum and maximum allowable storage capacities of the hydrogen tank, respectively.

\subsubsection{Reject burning unit agent}

This agent is responsible for announcing the range of power that can be generated by the RB power plant subject to operational constraints, fuel cost, O\&M cost, startup cost, and allowable emissions. The reject burning unit agent is also responsible for operating the RB power plant unit based on the received commands from the micro-grid agent.

The output power of the RB power plant at time step $t$ can be calculated by the following equation:

$$
P_{R B}(t)=\frac{H H V_{N O W} M_{N O W}(t)}{\eta_{R B} \Delta t},
$$

where $\eta_{R B}$ is the efficiency of the RB power plant and $H H V_{N O W}$ is the higher heating value of the non-organic fraction of the MSW. Also, $M_{N O W}(t)$ represents the amount of non-organics being fed to the RB power plant at time step $t$.

The fuel cost of the RB power plant at time step $t$ can be calculated by the following equation:

$$
\operatorname{cost}_{f u e l, R B}(t)=P_{R B}(t) B_{f u e l, R B} \Delta t,
$$

where $B_{f u e l, R B}$ is the fuel cost rate of the RP power plant that can be calculated by the following equation:

$$
B_{f u e l, R B}=\frac{B_{C}}{\eta_{R B} H H V_{N O W}},
$$

where $B_{C}$ is the cost of waste collection. The O\&M cost of the RB power plant at time step $t$ can be calculated according to the following equation:

$$
\operatorname{cost}_{O \& M, R B}(t)=u_{R B}(t) P_{R B}(t) B_{O \& M, R B} \Delta t,
$$

where $u_{R B}(t)$ is a binary variable, being equal to 1 during the operation of the RB power plant and 0 during other time steps, and $B_{O \& M, R B}$ is the O\&M cost rate of the RB power plant.

The startup cost of the RB power plant at time step $t$ can be defined by the following equation:

$$
\operatorname{cost}_{S U, R B}(t)=S_{R B}\left|u_{R B}(t)-u_{R B}(t-1)\right| \Delta t,
$$

where $S_{R B}$ is the startup cost rate of the RB power plant. The amount of air pollutants generated by the RB power plant at time step $t$ can be calculated by the following equation: 


$$
\operatorname{emission}_{R B}(t)=u_{R B}(t) P_{R B}(t) E_{R B} \Delta t,
$$

where $E_{R B}$ is the emission rate of RB power plant. The operation of the RB power plant at time step $t$ is subject to the following constraints:

$$
P_{R B, \min } \leq P_{R B}(t) \leq P_{R B, \max }
$$

where $P_{R B, \min }$ and $P_{R B, \max }$ are the minimum and maximum allowable output power of the RB power plant, respectively.

\subsubsection{Renewable agent}

This agent is responsible for announcing the output power of the wind turbine generator system considering the wind speed uncertainty, operational constraints, and O\&M cost. The renewable agent is also responsible for operating the wind turbine unit based on the micro-grid agent's commands.

The output power of the wind turbine system at time step $t$ can be described in terms of wind speed according to the following equation [37]:

$$
P_{W T}(t)= \begin{cases}0 & ; V<V_{\text {cut }- \text { in }}, V>V_{\text {cut }- \text { off }} \\ P_{\text {rated }} \times\left(\left(V(t)-V_{\text {cut-in }}\right) /\left(V_{\text {rated }}-V_{\text {cut-in }}\right)\right)^{3} & ; V_{\text {cut-in }} \leq V<V_{\text {rated }} \\ P_{\text {rated }} & ; V_{\text {rated }} \leq V \leq V_{\text {cut-off }}\end{cases}
$$

where $V_{c u t-i n}$ is the cut-in wind speed, $V_{c u t-o f f}$ is the cut-off wind speed, $V(t)$ is the wind speed at time step $t, V_{\text {rated }}$ is the nominal wind speed, and $P_{\text {rated }}$ is the nominal power of the wind turbine.

The uncertainty associated with wind speed is modeled using Weibull distribution according to the procedure that is described by Jabbari-Sabet et al. [38]. To this end, 1000 scenarios are generated according to the Monte Carlo simulation and micro-grid operation is analyzed under these scenarios.

The O\&M cost of the wind turbine generator system at time step $t$ can be calculated according to the following equation:

$$
\operatorname{cost}_{O \& M, W T}(t)=u_{W T}(t) P_{W T}(t) B_{O \& M, W T} \Delta t,
$$

where $u_{W T}(t)$ is a binary variable, being equal to 1 during the operation of the wind turbine and 0 during other time steps, and $B_{O \& M, W T}$ is the O\&M cost rate of the wind turbine generator system.

\subsubsection{Storage agent}

This agent is responsible for announcing the states of charge of the electrical and thermal storage units subject to operational constraints (e.g. the minimum and maximum allowable storage capacities of the electrical and thermal storage units, the initial states of charge of the storage units etc.), and O\&M costs to the micro-grid agent. The storage agent is also responsible for operating the electrical and thermal storage units according to the micro-grid agent's commands.

The O\&M cost of the electrical storage system at time step $t$ can be calculated according to the following equation:

$$
\operatorname{cost}_{O \& M, E S}(t)=u_{E S}(t) P_{E S}(t) B_{O \& M, E S} \Delta t
$$

where $u_{E S}(t)$ is a binary variable, being equal to 1 during the charging/discharging of the electrical storage system and 0 during other time steps, and $B_{O \& M, E S}$ is the O\&M cost rate of the electrical storage system.

Charge quantity of the electrical storage system (battery bank) at time step $t$ is obtained by the following equation:

$$
E_{E S}(t)=E_{E S}(t-1)+E_{E S, c h}(t)-E_{E S, d c h}(t),
$$

where $E_{E S, c h}(t)$ and $E_{E S, d c h}(t)$ denote the charging and discharging energy of the electrical storage system at time step $t$, respectively that are defined by the following equations:

$$
E_{E S, c h}(t)=\left|E_{E S, c h}(t) \eta_{E S, c h} \Delta t\right|
$$




$$
E_{E S, d c h}(t)=\left|\left(E_{E S, d c h}(t) / \eta_{E S, d c h}\right) \Delta t\right|,
$$

where $\eta_{E S, d c h}$ and $\eta_{E S, d c h}$ are the charge and discharge efficiencies of the electrical storage system, respectively.

Also, there are similar equations for the thermal storage system and only the $E S$ indices should be substituted by the ThS indices to represent them.

The operation of the electrical and thermal storage systems at time step $t$ is subject to the following constraints:

$$
\begin{gathered}
P_{E S, \text { min }} \leq P_{E S}(t) \leq P_{E S, \text { max }}, \\
P_{T h S, \min } \leq P_{T h S}(t) \leq P_{T h S, \text { max }},
\end{gathered}
$$

where $P_{E S, \min }, P_{E S, \max }, P_{T h S, \min }$, and $P_{T h S, \max }$ represent the minimum and maximum allowable output power of the electrical and thermal storage systems, respectively.

\subsubsection{Load aggregator agent}

This agent is responsible for aggregating the electrical and thermal loads, implementing a demand response program and announcing the aggregated loads to the micro-grid agent. This agent also models the uncertainties associated with the electrical and thermal loads using a normal distribution function according to the procedure that is described by Jabbari-Sabet et al. [38]. To this end, 1000 scenarios are generated using Monte Carlo simulation at each hour to analyze the performance of the micro-grid under uncertain conditions.

The aggregated electrical loads include both vital and non-vital loads. It is worth noting that the proportion of load considered non-vital is 15 percent of the total load at each time step $t$. The load aggregator is also responsible for aggregating the electrical and thermal loads incorporating the uncertainty associated with load forecasts whilst simultaneously implementing a demand response program and announcing these loads to the micro-grid agent. In this paper, we use the RTP method to reflect the actual real-time price of electricity that implements a demand response program. In RTP, consumers are informed about the market price in a day-ahead mechanism and adjust their consumption based on self- and cross-elasticities of electricity consumption that are considered to be -0.2 and 0.01 , respectively. It is worth noting that the self-elasticity coefficient relates the electrical demand during one hour to the price during that one hour and the cross-elasticity coefficient relates the demand during one hour to the price during other hours. As well as other forms of demand response, RTP can reduce and/or transfer the peak load energy requirements. The demand response program implemented in this paper uses the same procedure that is described by N. Nikmehr et al. [24].

\subsection{Agents communication}

Below, Fig. 3 shows the communication channels used for data exchange in this MAS model. In this figure, the numbers indicate the sequence of messages sent between the agents. The messages are sent after every hour.

1: The upstream network agent sends the hourly price of purchasing and selling electricity on the up-stream wholesale market; the price of purchasing the natural gas; and the electrical power exchange restrictions to the micro-grid operator.

2: The micro-grid agent requests the thermal agent, hydrogen agent, RB unit agent, and storage agent to announce the total amount of electricity they can generate, requests the renewable agent to announce its generated power considering the uncertainty associated with wind power generation forecasts, and requests the load aggregator agent to announce the total amount of electrical and thermal loads as well as the amount of electrical load that can be deferred considering the uncertainty associated with their forecasted values.

3: The field layer agents respond to the micro-grid agent's request and provide the requested information.

4: The micro-grid agent requests the upstream network agent to compensate the shortage of power or buy the surplus power.

5: The upstream network agent sends the confirmation of the buying or selling the power to the micro-grid agent.

6: The micro-grid agent sends the commands on the operation of the micro-grid components to the field layer agents. 


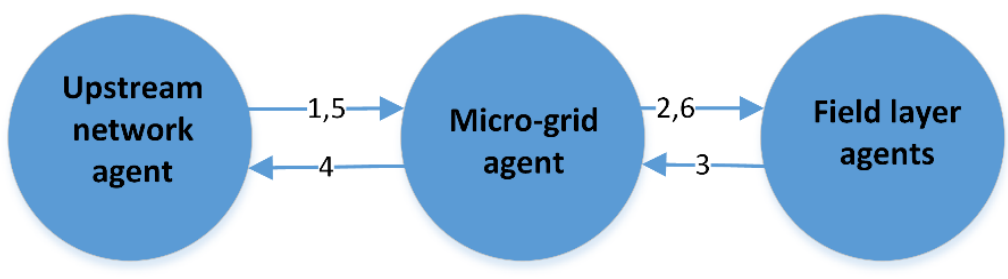

Fig. 3. Data exchange in the proposed MAS.

\section{Results and discussion}

The simulation of the proposed MAS is performed using MATLAB software. The data required for optimal operation of the micro-grid are shown in the following tables: The specifications of the micro-turbine, fuel cell, boiler, hydrogen tank, RB power plant, and the wind turbine generator system are shown in Tables 1-5 [37,39,40]. Table 6 represents the mean and variance of the wind speed data that are denoted by $\mu$ and $\sigma^{2}$, respectively. The mean and variance of the electrical and thermal load demands are shown in Tables 7 and 8, respectively. We have provided the mean and variance of the wind speed $[\mathrm{m} / \mathrm{s}]$ and electrical and thermal loads $[\mathrm{kW}]$ since they are needed for modeling the uncertainty associated with their forecasted values according to the procedure that is described by Jabbari-Sabet et al. [38]. The specifications of the electrical and thermal storage systems are shown in Table 9 [39]. The day-ahead hourly forecast of the electricity market is shown in Table 10. Also, the price of natural gas and the specifications of the upstream power grid are shown in Table 11 [39].

Table 1. Specifications of the micro-turbine and fuel cell [39].

\begin{tabular}{|c|c|c|c|c|c|c|c|c|c|c|c|c|}
\hline & \multicolumn{3}{|c|}{$\begin{array}{c}\text { Emission factors } \\
{[\mathrm{kg} / \mathrm{MWh}]}\end{array}$} & \multicolumn{2}{|c|}{ Cost factors } & \multicolumn{2}{|c|}{$\begin{array}{c}\text { Electrical } \\
\text { power } \\
\text { range }[\mathrm{kW}]\end{array}$} & \multicolumn{2}{|c|}{$\begin{array}{c}\text { Thermal } \\
\text { power } \\
\text { range }[\mathrm{kW}]\end{array}$} & \multirow{2}{*}{$\begin{array}{c}\text { Efficiency } \\
{[\%]}\end{array}$} & \multirow[t]{2}{*}{ Fuel cost } & \multirow{2}{*}{$K_{\text {Thermal }}$} \\
\hline & $N O_{x}$ & $\mathrm{CO}_{2}$ & $\mathrm{SO}_{2}$ & $\begin{array}{c}\text { Start- } \\
\text { up cost } \\
{[\$]}\end{array}$ & $\begin{array}{c}\text { O\&M } \\
\text { cost } \\
{[\$ / k W h]}\end{array}$ & Min & Max & Min & Max & & & \\
\hline MT & 0.2 & 724 & 0.0036 & 0.11 & 0.005 & 6 & 30 & 15.6 & 78 & 26 & $0.41 \$ / \mathrm{m}^{3}$ & 2.6 \\
\hline $\mathrm{FC}$ & 0.0136 & 489 & 0.0027 & 0.148 & 0.008 & 3 & 25 & 4.2 & 35 & 40 & $0.12 \$ / \mathrm{kWh}$ & 1.4 \\
\hline
\end{tabular}

Table 2. Boiler's specifications [40].

\begin{tabular}{ccccccc}
\hline & \multicolumn{2}{c}{$\begin{array}{c}\text { Emission factors } \\
{[\mathrm{kg} / \mathrm{MWh}]}\end{array}$} & \multicolumn{2}{c}{$\begin{array}{c}\text { Thermal } \\
\text { power } \\
\text { range }[\mathrm{kW}]\end{array}$} & \multirow{2}{*}{$\begin{array}{c}\text { Efficiency } \\
{[\%]}\end{array}$} \\
\cline { 2 - 5 } & $\mathrm{NO}_{x}$ & $\mathrm{CO}_{2}$ & $\mathrm{SO}_{2}$ & Min & $\mathrm{Max}$ & \\
\hline Boiler & 1.812 & 845 & 2.545 & 3 & 80 & 90 \\
\hline
\end{tabular}

Table 3. Hydrogen tank's specifications [40].

\begin{tabular}{ccccc}
\hline & \multirow{2}{*}{ O\&M cost } & \multicolumn{3}{c}{ Storage status $\left[\mathrm{m}^{3}\right]$} \\
\cline { 3 - 4 } & & Initial & Min & Max \\
\hline Hydrogen tank & 0.002 & 50 & 0 & 120 \\
\hline
\end{tabular}

Table 4. Reject burning power plant's specifications [39].

\begin{tabular}{|c|c|c|c|c|c|c|c|c|c|c|}
\hline & \multicolumn{3}{|c|}{$\begin{array}{c}\text { Emission factors } \\
{[\mathrm{kg} / \mathrm{MWh}]}\end{array}$} & \multicolumn{2}{|c|}{ Cost factors } & \multicolumn{2}{|c|}{$\begin{array}{c}\text { Electrical } \\
\text { power range } \\
{[\mathrm{kW}]}\end{array}$} & \multirow{2}{*}{$\begin{array}{c}\text { Efficiency } \\
{[\%]}\end{array}$} & \multirow{2}{*}{$\begin{array}{l}\text { Fuel cost } \\
{[\$ / \mathrm{kWh}]}\end{array}$} & \multirow{2}{*}{$\begin{array}{l}H H V_{N O W} \\
{[\mathrm{MJ} / \mathrm{kg}]}\end{array}$} \\
\hline & $N O_{x}$ & $\mathrm{CO}_{2}$ & $\mathrm{SO}_{2}$ & $\begin{array}{c}\text { Start-up } \\
\text { cost } \\
{[\$]}\end{array}$ & $\begin{array}{c}\text { O\&M } \\
\text { cost } \\
{[\$ / k W h]}\end{array}$ & Min & Max & & & \\
\hline RB & 0.2 & 300 & 0.1 & 0.12 & 0.006 & 6 & 30 & 30 & 0.02 & 35.7 \\
\hline
\end{tabular}


Table 5. Wind turbine generator system's specifications [37].

\begin{tabular}{cccccc}
\hline & $\begin{array}{c}V_{\text {cut-in }} \\
{[\mathrm{m} / \mathrm{s}]}\end{array}$ & $\begin{array}{c}V_{\text {cut-off }} \\
{[\mathrm{m} / \mathrm{s}]}\end{array}$ & $\begin{array}{c}V_{\text {rated }} \\
{[\mathrm{m} / \mathrm{s}]}\end{array}$ & $\begin{array}{c}P_{\text {rated }} \\
{[\mathrm{kW}]}\end{array}$ & $\begin{array}{l}\text { O\&M } \\
\text { cost } \\
{[\$ / \mathrm{kWh}]}\end{array}$ \\
\hline WT & 2.5 & 15 & 11 & 15 & 0.007 \\
\hline
\end{tabular}

Table 6. Wind speed data.

\begin{tabular}{ccccccccc}
\hline Hour & 1 & 2 & 3 & 4 & 5 & 6 & 7 & 8 \\
\hline$\mu$ & 12.68 & 13.47 & 11.34 & 6.96 & 9.25 & 11.14 & 5.67 & 4.84 \\
\hline$\sigma^{2}$ & 4.57 & 8.64 & 10.89 & 6.40 & 7.84 & 4.84 & 6.65 & 4.66 \\
\hline Hour & 9 & 10 & 11 & 12 & 13 & 14 & 15 & 16 \\
\hline$\mu$ & 8.64 & 13.86 & 14.88 & 15.24 & 20.32 & 10.02 & 19.62 & 15.98 \\
\hline$\sigma^{2}$ & 5.76 & 19.62 & 5.66 & 7.29 & 6.86 & 15.05 & 15.28 & 16.97 \\
\hline Hour & 17 & 18 & 19 & 20 & 21 & 22 & 23 & 24 \\
\hline$\mu$ & 12.73 & 21.39 & 17.34 & 21.17 & 12.91 & 9.55 & 14.53 & 8.77 \\
\hline$\sigma^{2}$ & 19.09 & 19.09 & 15.28 & 6.20 & 11.90 & 19.36 & 9.98 & 9 \\
\hline
\end{tabular}

Table7. Electrical load data.

\begin{tabular}{ccccccccc}
\hline Hour & 1 & 2 & 3 & 4 & 5 & 6 & 7 & 8 \\
\hline$\mu$ & 52.94 & 49.45 & 50.39 & 50.67 & 55.87 & 62.61 & 71.28 & 76.56 \\
\hline$\sigma^{2}$ & 19.81 & 23.31 & 11.24 & 15.37 & 24.27 & 28.94 & 34.55 & 40.00 \\
\hline Hour & 9 & 10 & 11 & 12 & 13 & 14 & 15 & 16 \\
\hline$\mu$ & 75.42 & 80.58 & 76.70 & 73.46 & 70.86 & 70.87 & 74.30 & 81.85 \\
\hline$\sigma^{2}$ & 53.24 & 27.53 & 35.40 & 38.81 & 37.98 & 49.13 & 49.95 & 48.77 \\
\hline Hour & 17 & 18 & 19 & 20 & 21 & 22 & 23 & 24 \\
\hline$\mu$ & 85.97 & 89.30 & 90.49 & 87.37 & 78.80 & 70.99 & 64.66 & 55.14 \\
\hline$\sigma^{2}$ & 36.74 & 44.53 & 54.01 & 61.20 & 38.86 & 46.85 & 39.77 & 16.97 \\
\hline
\end{tabular}

Table 8. Thermal load data.

\begin{tabular}{ccccccccc}
\hline Hour & 1 & 2 & 3 & 4 & 5 & 6 & 7 & 8 \\
\hline$\mu$ & 39.38 & 44.55 & 41.87 & 48.77 & 66.56 & 68.20 & 72.78 & 90.44 \\
\hline$\sigma^{2}$ & 11.21 & 16.48 & 17.52 & 23.50 & 31.76 & 39.30 & 48.87 & 65.60 \\
\hline Hour & 9 & 10 & 11 & 12 & 13 & 14 & 15 & 16 \\
\hline$\mu$ & 92.80 & 91.81 & 97.21 & 92.66 & 91.01 & 86.95 & 88.87 & 94.92 \\
\hline$\sigma^{2}$ & 58.11 & 59.23 & 82.44 & 82.12 & 68.45 & 66.11 & 85.86 & 56.88 \\
\hline Hour & 17 & 18 & 19 & 20 & 21 & 22 & 23 & 24 \\
\hline$\mu$ & 109.52 & 113.50 & 113.15 & 93.59 & 93.00 & 82.03 & 76.06 & 68.40 \\
\hline$\sigma^{2}$ & 80.27 & 131.76 & 136.65 & 66.69 & 48.34 & 69.74 & 45.20 & 34.64 \\
\hline
\end{tabular}

Table 9. Electrical and thermal storage units' specifications [39].

\begin{tabular}{ccccccc}
\hline & $\begin{array}{c}\text { O\&M cost } \\
{[\$ / \mathrm{kWh}]}\end{array}$ & Min & Power range $[\mathrm{kW}]$ & \multicolumn{3}{c}{ Storage status $[\mathrm{kWh}]$} \\
\cline { 3 - 7 } & 0.002 & -30 & 30 & Initial & Min & Max \\
\hline ES & 0.002 & -30 & 30 & 150 & 30 & 300 \\
\hline ThSS & & & & 150 & 30 & 300 \\
\hline
\end{tabular}

Table 10. Electricity price.

\begin{tabular}{ccccccccc}
\hline Hour & 1 & 2 & 3 & 4 & 5 & 6 & 7 & 8 \\
\hline $\begin{array}{c}\text { Price } \\
{[\$ \mathrm{kWh}]}\end{array}$ & 0.11 & 0.11 & 0.11 & 0.11 & 0.11 & 0.110 & 0.13 & 0.13 \\
\hline Hour & 9 & 10 & 11 & 12 & 13 & 14 & 15 & 16 \\
\hline $\begin{array}{c}\text { Price } \\
{[\$ \mathrm{kWh}]}\end{array}$ & 0.13 & 0.13 & 0.13 & 0.15 & 0.15 & 0.15 & 0.18 & 0.18 \\
\hline Hour & 17 & 18 & 19 & 20 & 21 & 22 & 23 & 24 \\
\hline $\begin{array}{c}\text { Price } \\
{[\$ / \mathrm{kWh}]}\end{array}$ & 0.18 & 0.24 & 0.24 & 0.24 & 0.18 & 0.15 & 0.15 & 0.11 \\
\hline
\end{tabular}


Table 11. Upstream natural gas and power networks' specifications [39].

\begin{tabular}{ccc}
\hline $\begin{array}{c}\text { Natural gas price } \\
{\left[\$ / \mathrm{m}^{3}\right]}\end{array}$ & \multicolumn{2}{c}{ Range of electrical power exchange $[\mathrm{kW}]$} \\
\cline { 2 - 3 } & Min & Max \\
\hline 0.41 & -30 & 30 \\
\hline
\end{tabular}

Figure 4 shows the day-ahead energy management of the power system components of the proposed micro-grid considering the uncertainty associated with day-ahead forecasted values of electrical loads, thermal loads, and wind power generation. As can be seen in Fig. 4, the amount of sold electricity to the upstream power grid is more than the amount of purchased electricity from the upstream power grid. The total electrical energy exchanged between the micro-grid and the upstream power grid during the day is equal to $-110.54 \mathrm{kWh}$. Therefore, the energy exchange between the micro-grid and the upstream power grid makes a profit for the micro-grid. This is because according to the above tables, it is assumed that power generation in the micro-grid is always cheaper than buying electricity from the upstream power grid. Trough exchanging the electrical power with the upstream power grid, the micro-grid operator has earned $\$ 17.06$. Indeed, this income has reduced the micro-grid operational costs. The cost of electrical energy generated by the RB power plant is less than the fuel cell. On the other hand, the fuel cell is more environmentally friendly than the RB power plant. However, the share of power supplied by the RB power plant is more than the fuel cell. In addition, the cost of electrical energy generated by the RB power plant is less than the micro-turbine and the micro-turbine is more environmentally friendly than the RB power plant. The micro-turbine unit is a combined heat and power unit and based on Tables 1 and $2, K_{\text {Thermal,MT }}$ is higher than $K_{\text {Thermal,FC}}$. Therefore, when the electrical output power of the micro-turbine is low, there will be a shortage of the required thermal energy, this in turn increases the operating time of the boiler. The boiler is a polluting unit, therefore, the share of the microturbine in supplying the electrical load is more than the RB power plant.

Figure 5 shows the amount of thermal energy produced by the thermal components of the proposed micro-grid. As can be seen in Fig. 5, at the $19^{\text {th }}$ hour, the amount of discharging thermal energy of the thermal storage system is equal to $2.83 \mathrm{kWh}$ and this still cannot satisfy the thermal load; therefore, the boiler is operated to compensate the shortage of thermal energy. During the $20^{\text {th }}-22^{\text {th }}$ hours, since the amount of thermal energy that is stored in the thermal storage system has reached its lower limit, the boiler is started to compensate the shortage of thermal energy. At the $23^{\text {rd }}$ hour, the amount of thermal energy generated by the micro-turbine and fuel cell is greater than the thermal load of the microturbine; therefore, the thermal storage system operates in a charging mode. At the $24^{\text {th }}$ hour, a similar situation like the $19^{\text {th }}$ hour has occurred. The micro-grid operation cost is equal to $\$ 103.84$ and the amount of emissions generated is equal to $728.65 \mathrm{~kg}$. The results show that the amount of emissions produced per $\mathrm{kWh}$ of electrical energy is equal to $0.448 \mathrm{CO} 2 / \mathrm{KWh}$ which is less than the considered upper limit of $0.664 \mathrm{~kg}$ per $\mathrm{kWh}$.
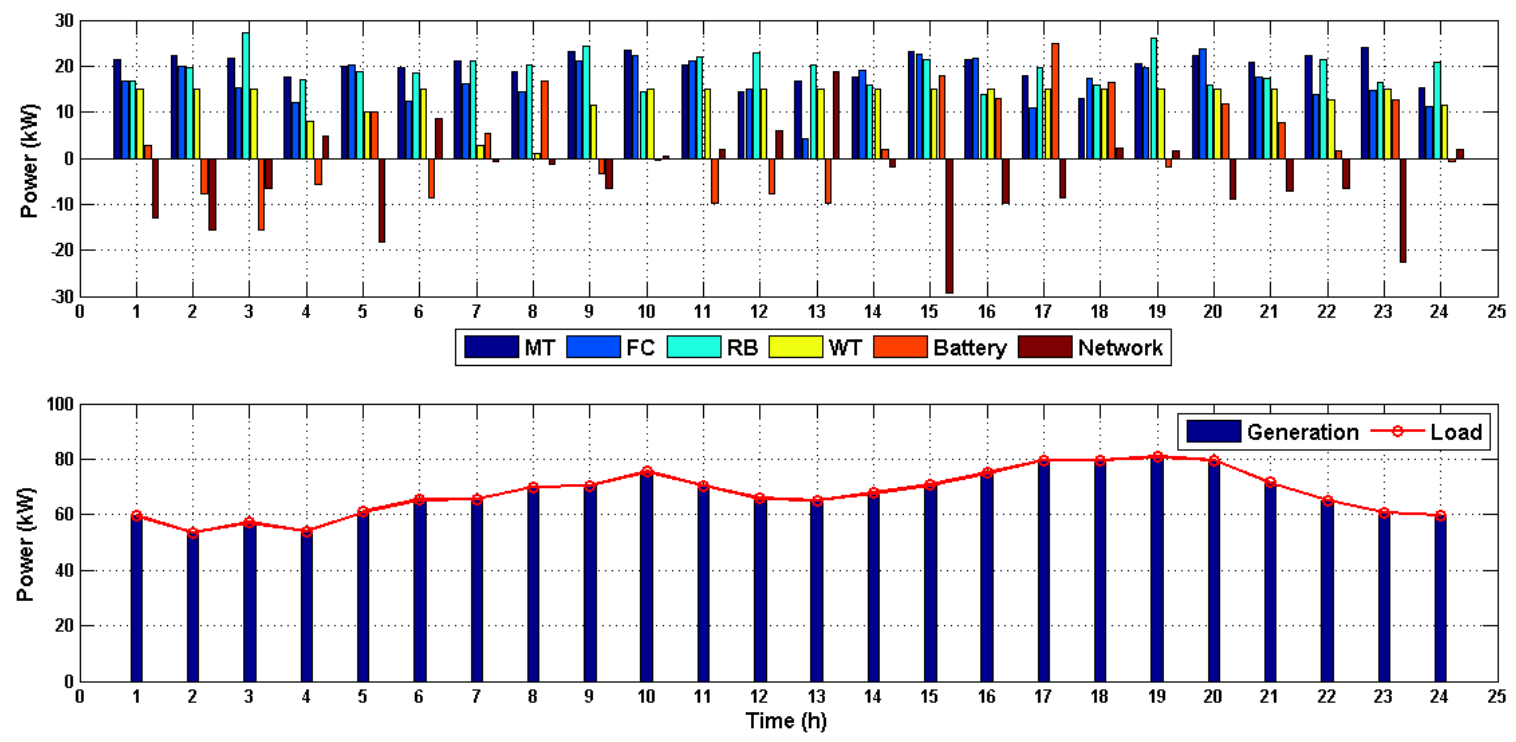

Fig. 4. Optimal energy management of the electrical components considering the uncertainties. 

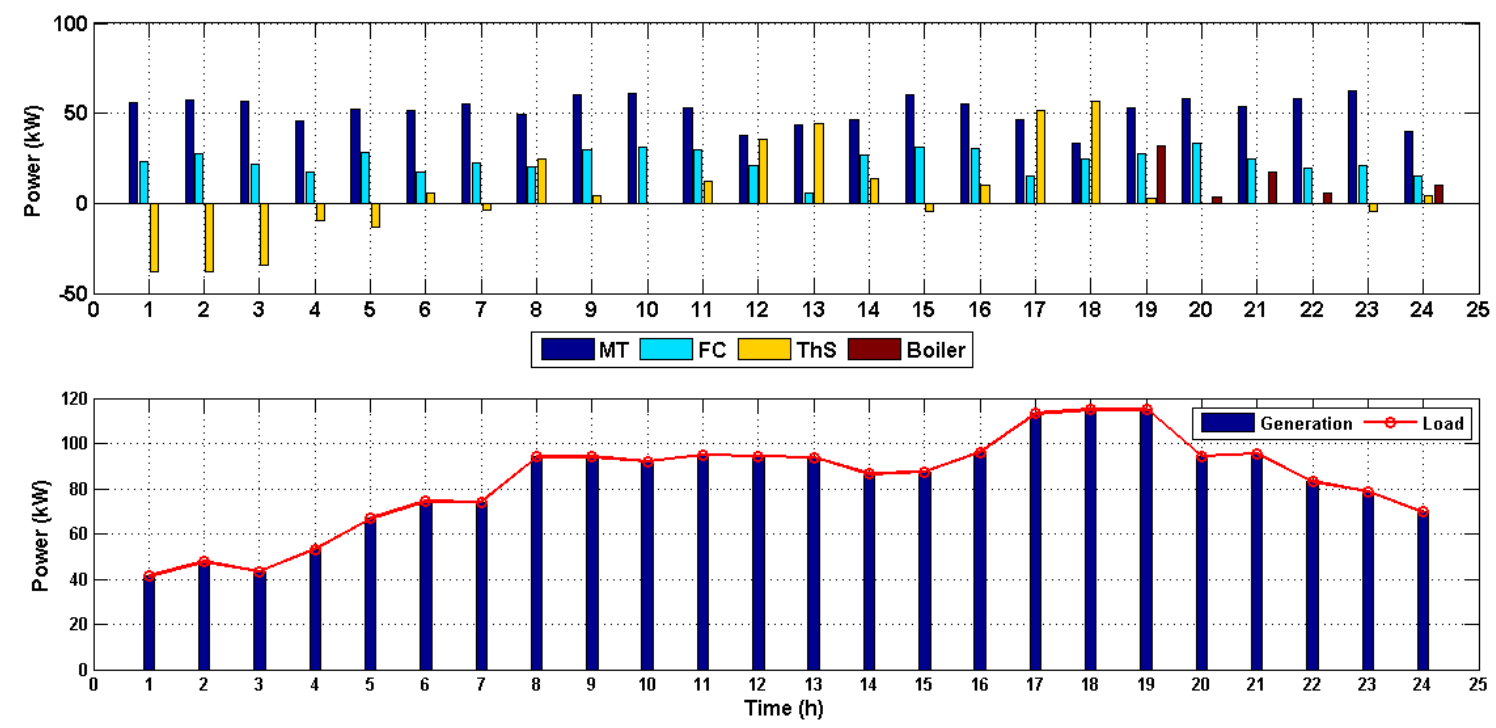

Fig. 5. Optimal energy management of the thermal components considering the uncertainties.

Due to the absence of similar structures in the literature, it is difficult to compare our results with the results obtained by other methodologies. Alternatively, in order to validate our results, the two following scenarios are examined.

\subsection{Scenario1: Lack of waste}

In this scenario, it is supposed that the amount of MSW is equal to zero. Also, it is assumed that the hydrogen stored in the hydrogen tank has reached the minimum allowable storage capacity. Table 12 shows the energy management of the proposed micro-grid under this scenario. As can be seen in this table, the output energy of the RB power plant is equal to zero at every hour. Also, there is no available hydrogen to be fed to the fuel cell. Therefore, the output energy of the fuel cell is also equal to zero at every hour. In this situation, the lack of electrical energy is compensated by the upstream network. From Table 12, it is evident that the upper limit of power exchange between the upstream network and micro-grid cannot be equal to $30 \mathrm{kWh}$ in this situation. Therefore, it is necessary to increase the energy exchange restriction of the micro-grid so that the system remains stable in this situation.

Table 12. Energy management of the proposed micro-grid under scenario1.

\begin{tabular}{cccccc}
\hline Hour & MT & FC & RB & ESS & Network \\
\hline 1 & 15.4253 & 0 & 0 & -8.7730 & 37.9787 \\
\hline 2 & 12.8789 & 0 & 0 & 19.3519 & 6.1702 \\
\hline 3 & 25.6709 & 0 & 0 & 13.8164 & 2.6260 \\
\hline 4 & 21.0122 & 0 & 0 & 8.0759 & 16.8822 \\
\hline 5 & 22.6033 & 0 & 0 & -9.2415 & 37.5119 \\
\hline 6 & 22.2930 & 0 & 0 & 5.0173 & 23.0079 \\
\hline 7 & 24.4380 & 0 & 0 & 17.1955 & 21.3132 \\
\hline 8 & 17.5093 & 0 & 0 & -6.1586 & 57.5745 \\
\hline 9 & 23.5626 & 0 & 0 & 1.5724 & 33.6701 \\
\hline 10 & 22.9970 & 0 & 0 & -15.6936 & 53.0950 \\
\hline 11 & 25.7151 & 0 & 0 & 0.5025 & 29.2213 \\
\hline 12 & 23.3055 & 0 & 0 & 4.6064 & 22.8255 \\
\hline 13 & 15.5542 & 0 & 0 & 14.2932 & 20.2862 \\
\hline 14 & 11.6241 & 0 & 0 & 9.6427 & 31.5513 \\
\hline 15 & 14.2578 & 0 & 0 & 11.9172 & 29.4450 \\
\hline 16 & 24.1373 & 0 & 0 & -0.4384 & 36.2418 \\
\hline 17 & 20.7508 & 0 & 0 & 0.1877 & 43.6955 \\
\hline 18 & 17.5699 & 0 & 0 & 1.6579 & 45.4440 \\
\hline 19 & 19.0283 & 0 & 0 & 14.0839 & 32.6344 \\
\hline 20 & 25.2504 & 0 & 0 & 7.0480 & 32.1698 \\
\hline 21 & 17.1505 & 0 & 0 & 2.1302 & 37.2356 \\
\hline 22 & 21.3798 & 0 & 0 & 17.0762 & 14.0397 \\
\hline 23 & 18.7112 & 0 & 0 & 11.4744 & 15.5504 \\
\hline
\end{tabular}




\begin{tabular}{llllll}
\hline 24 & 17.4885 & 0 & 0 & -4.7142 & 35.5577 \\
\hline
\end{tabular}

\subsection{Scenario2: Reduced wind speed}

In this scenario, it is assumed that the wind speed profile is reduced to $60 \%$ of the primary wind speed. In this case, the percentage of the total energy produced by the wind generator system to the total electrical load is decreased from $19.26 \%$ under normal operating conditions to $11.07 \%$. Table 13 shows the energy management of the proposed microgrid under the second scenario. Following the reduction of the amount of electrical energy produced by the wind turbine, other units are forced to increase their production of electrical energy. On the other hand, since the wind turbine is a zero-emission system, this increase should be performed such that it still satisfies the emissions constraint. The results clearly show that the amount of purchased energy from the upstream power grid is increased under this scenario.

Table 13. Energy management of the proposed micro-grid under scenario2.

\begin{tabular}{|c|c|c|c|c|c|c|}
\hline Hour & MT & $\mathrm{FC}$ & RB & WT & ESS & Network \\
\hline 1 & 18.7581 & 17.5863 & 18.6031 & 6.1485 & 0.0446 & -1.5096 \\
\hline 2 & 21.8613 & 24.7806 & 21.3583 & 10.1660 & -9.5750 & -15.1902 \\
\hline 3 & 24.1582 & 20.6729 & 18.7033 & 4.0724 & -6.4628 & -4.0307 \\
\hline 4 & 24.5951 & 20.5403 & 10.6053 & 1.2730 & -0.5555 & -2.5442 \\
\hline 5 & 11.1446 & 14.2560 & 29.0588 & 1.7996 & 5.4685 & -0.8032 \\
\hline 6 & 6.8958 & 17.7852 & 19.4576 & 4.0864 & 19.0801 & -1.9868 \\
\hline 7 & 20.8889 & 13.1415 & 21.4296 & 0.1614 & -3.1404 & 13.1907 \\
\hline 8 & 7.6468 & 24.8385 & 14.6558 & 0 & 12.2428 & 10.6366 \\
\hline 9 & 20.9975 & 19.4158 & 20.1871 & 2.2073 & 1.0947 & 6.5224 \\
\hline 10 & 17.4195 & 17.8828 & 21.3998 & 7.5387 & 16.3387 & -5.1812 \\
\hline 11 & 21.7496 & 22.4426 & 19.3496 & 12.6967 & -0.0140 & -5.7874 \\
\hline 12 & 21.9213 & 5.1694 & 22.3040 & 10.8361 & 11.5640 & -6.0576 \\
\hline 13 & 24.5274 & 18.1973 & 24.5286 & 15.0000 & -4.8068 & -12.3130 \\
\hline 14 & 20.2825 & 22.5290 & 15.5200 & 3.3925 & 3.5214 & 2.5727 \\
\hline 15 & 24.3818 & 9.0230 & 13.4256 & 15.0000 & -8.0584 & 16.8480 \\
\hline 16 & 23.4900 & 22.4167 & 20.3981 & 12.1644 & 20.2163 & -23.7448 \\
\hline 17 & 16.2529 & 13.6697 & 19.6765 & 8.4658 & 14.3102 & 7.2577 \\
\hline 18 & 17.6221 & 13.4639 & 21.3435 & 15.0000 & 20.4585 & -8.2174 \\
\hline 19 & 26.3278 & 23.1022 & 14.5806 & 15.0000 & -22.5566 & 24.2926 \\
\hline 20 & 23.7436 & 10.6553 & 15.7960 & 15.0000 & 9.6928 & 4.6102 \\
\hline 21 & 22.1582 & 10.5180 & 22.1330 & 7.4938 & -2.9998 & 12.2131 \\
\hline 22 & 20.2609 & 15.2093 & 18.8918 & 2.4772 & 19.7839 & -11.4909 \\
\hline 23 & 20.6178 & 17.2657 & 14.0531 & 7.4940 & -9.3261 & 10.6314 \\
\hline 24 & 13.0974 & 19.2637 & 16.1345 & 2.1933 & 12.4472 & -3.2378 \\
\hline
\end{tabular}

\section{Conclusion and future work}

This study developed a cutting-edge MAS solution for optimal operation of a grid-connected multiple energy carrier micro-grid incorporating RTP demand response and the uncertainty associated with day-ahead forecasts. In this regard, several agents represent the power system at three hierarchical layers. The communication process of the agents are described and their mathematical models are formulated. The main advantage of the proposed agent-based method is simplicity that has a key role in moving towards sustainable development of the multiple energy carrier micro-grids. This research also demonstrates that by using the proposed architecture, several uncertain parameters can be managed and the RTP demand response program can be performed without facing a complex modeling scheme.

The results show that using the micro-turbine and the fuel cell as combined heat and power units, combined with thermal storage, is an efficient way for satisfying the thermal loads in the proposed grid-connected multiple energy carrier micro-grid. In addition, the proposed model was shown to be robust under various scenarios. The model shows that the total cost of the micro-grid operation can be minimized while satisfying an exogenous emission constraint.

Future work will concentrate on developing an agent-based framework where the micro-grid is not just a passive price taker but to take into account that its operational decisions that might affect the market prices. A further addition might 
be to incorporate carbon price into the cost structure so that emissions are not constrained exogenously but are endogenous to the model.

\section{References}

[1] Y. Li, W. Liang, and R. Tan, "Optimal design of installation capacity and operation strategy for distributed generation system," Applied Thermal Engineering, Vol. 125, pp. 756-766 (2017). https://doi.org/10.1016/j.applthermaleng.2017.07.011.

[2] J. Allison, "Robust multi-objective control of hybrid renewable microgeneration systems with energy storage," Applied Thermal Engineering, Vol. 114, pp. 1498-1506 (2017). https://doi.org/10.1016/j.applthermaleng.2016.09.070.

[3] S. Mohseni and S. M. Moghaddas-Tafreshi, "A multi-agent system for optimal sizing of a cooperative selfsustainable multi-carrier microgrid," Sustainable Cities and Society, Vol. 38, pp. 452-465 (2018). https://doi.org/10.1016/j.scs.2018.01.016.

[4] S. Väisänen, M. Mikkilä, J. Havukainen, L. Sokka, M. Luoranen, and M. Horttanainen, "Using a multimethod approach for decision-making about a sustainable local distributed energy system: A case study from Finland," Journal of Cleaner Production, Vol. 137, pp. 1330-1338 (2016). https://doi.org/10.1016/j.jclepro.2016.07.173.

[5] G. Yang and X. Zhai, "Optimization and performance analysis of solar hybrid CCHP systems under different operation strategies,” Applied Thermal Engineering, Vol. 133, pp. 327-340 (2018). https://doi.org/10.1016/j.applthermaleng.2018.01.046.

[6] Z. Luo, Z. Wu, Z. Li, H. Y. Cai, B. J. Li, and W. Gu, "A two-stage optimization and control for CCHP microgrid energy management," Applied Thermal Engineering, Vol. 125, pp. 513-522 (2017). https://doi.org/10.1016/j.applthermaleng.2017.05.188.

[7] K. P. Kumar and B. Saravanan, "Recent techniques to model uncertainties in power generation from renewable energy sources and loads in microgrids - A review," Renewable and Sustainable Energy Reviews, Vol. 71, pp. 348-358 (2017). https://doi.org/10.1016/j.rser.2016.12.063.

[8] M. Melamed, A. Ben-Tal, and B. Golany, "A multi-period unit commitment problem under a new hybrid uncertainty set for a renewable energy source," Renewable Energy, Vol. 118, pp. 909-917 (2018). https://doi.org/10.1016/j.renene.2016.05.095.

[9] J. L. Bernal-Agustín, R. Dufo-López, "Simulation and optimization of stand-alone hybrid renewable energy systems," Renewable \& Sustainable Energy Reviews, Vol. 13, pp. 2111-2118 (2009). https://doi.org/10.1016/j.rser.2009.01.010.

[10] J. Van Roy, N. Leemput, F. Geth, J. Büscher, R. Salenbien, and J. Driesen, "Electric vehicle charging in an office building microgrid with distributed energy resources," IEEE Transactions on Sustainable Energy, Vol. 5, pp. 1389-1396 (2014). https://doi.org/10.1109/TSTE.2014.2314754.

[11] R. Lasseter, A. Akhil, C. Marnay, J. Stephens, J. Dagle, R. Guttromson, A. Meliopoulos, R. Yinger, and J. Eto, White paper on Integration of Distributed Energy Resources: The CERTS Microgrid Concept (CERTS, CA, Rep. LBNL-50829, 2002). https://doi.org/10.2172/799644.

[12] M. Nazari-Heris, S. Abapour, and B. Mohammadi-Ivatloo, "Optimal economic dispatch of FC-CHP based heat and power micro-grids," Applied Thermal Engineering, Vol. 114, pp. 756-769 (2017). https://doi.org/10.1016/j.applthermaleng.2016.12.016.

[13] M. Elsied, A. Oukaour, H. Gualous, and O. A. Lo Brutto "Optimal economic and environment operation of micro-grid power systems,” Energy Conversion and Management, Vol. 122, pp. 182-194 (2016). https://doi.org/10.1016/j.enconman.2016.05.074.

[14] T. Niknam, F. Golestaneh, and A. Malekpour, "Probabilistic energy and operation management of a microgrid containing wind/photovoltaic/fuel cell generation and energy storage devices based on point estimate method and self-adaptive gravitational search algorithm," Energy, Vol. 43, no. 1, pp. 427-437 (2012). https://doi.org/10.1016/j.energy.2012.03.064.

[15] A. Hussain, V.-L. Bui, and H.-M. Kim, "Optimal operation of hybrid microgrids for enhancing resiliency considering feasible islanding and survivability," IET Renewable Power Generation, Vol. 11, no. 6, pp. 846-857 (2017). https://doi.org/10.1049/iet-rpg.2016.0820.

[16] S. Mohammadi, S. Soleymani, and B. Mozafari, "Scenario-based stochastic operation management of MicroGrid including Wind, Photovoltaic, Micro-Turbine, Fuel Cell and Energy Storage Devices," 
International Journal of Electrical Power \& Energy Systems, Vol. 54, pp. 525-535 (2014). https://doi.org/10.1016/j.ijepes.2013.08.004.

[17] H. Louie, "Operational analysis of hybrid solar/wind microgrids using measured data," Energy for Sustainable Development, Vol. 31, pp. 108-117 (2016). https://doi.org/10.1016/j.esd.2016.01.003.

[18] Y. Zhang, T. Zhang, R. Wang, Y. Liu, and B. Guo, " Optimal operation of a smart residential microgrid based on model predictive control by considering uncertainties and storage impacts," Solar Energy, Vol. 122, pp. 1052-1065 (2015). https://doi.org/10.1016/j.solener.2015.10.027.

[19] N. Nikmehr and S. Najafi-Ravadanegh, "Optimal operation of distributed generations in micro-grids under uncertainties in load and renewable power generation using heuristic algorithm," IET Renewable Power Generation, Vol. 9, no. 8, pp. 982-990 (2015). https://doi.org/10.1049/iet-rpg.2014.0357.

[20] A. Rabiee, M. Sadeghi, J. Aghaeic, and A. Heidari, "Optimal operation of microgrids through simultaneous scheduling of electrical vehicles and responsive loads considering wind and PV units uncertainties,"

Renewable and Sustainable Energy Reviews, Vol. 57, pp. 721-739 (2016).

https://doi.org/10.1016/j.rser.2015.12.041.

[21] B. Zhao, X. Zhang, P. Li, K. Wang, M. Xue, and C. Wang, "Optimal sizing, operating strategy and operational experience of a stand-alone microgrid on Dongfushan Island," Applied Energy, Vol. 113, pp. 1656-1666 (2014). https://doi.org/10.1016/j.apenergy.2013.09.015.

[22] S. Mohammadi, B. Mozafari, S. Solimani, and T. Niknam, "An adaptive modified firefly optimization algorithm based on Hong's point estimate method to optimal operation management in a microgrid with consideration of uncertainties," Energy, Vol. 51, pp. 339-348 (2013).

https://doi.org/10.1016/j.energy.2012.12.013.

[23] A. Baziar and A. Kavousi-Fard, "Considering uncertainty in the optimal energy management of renewable micro-grids including storage devices," Renewable Energy, Vol. 59, pp. 158-166 (2013). https://doi.org/10.1016/j.renene.2013.03.026.

[24] N. Nikmehr, S. Najafi-Ravadanegh, and A. Khodaei, "Probabilistic optimal scheduling of networked microgrids considering time-based demand response programs under uncertainty," Applied Energy, Vol. 198, pp. 267-279 (2017). https://doi.org/10.1016/j.apenergy.2017.04.071.

[25] T. Niknam, R. Azizpanah-Abarghooee, and M. R. Narimani, "An efficient scenario-based stochastic programming framework for multi-objective optimal micro-grid operation," Applied Energy, Vol. 99, pp. 455-470 (2012). https://doi.org/10.1016/j.apenergy.2012.04.017.

[26] A. Dolatabadi and B. Mohammadi-Ivatloo, "Stochastic risk-constrained scheduling of smart energy hub in the presence of wind power and demand response," Applied Thermal Engineering, Vol. 123, pp. 40-49 (2017). https://doi.org/10.1016/j.applthermaleng.2017.05.069.

[27] S. Bracco, F. Delfino, F. Pampararo, M. Robba, and M. Rossi, "A mathematical model for the optimal operation of the University of Genoa Smart Polygeneration Microgrid: Evaluation of technical, economic and environmental performance indicators," Energy, Vol. 64, pp. 912-922 (2014). https://doi.org/10.1016/j.energy.2013.10.039.

[28] C.-S. Karavas, G. Kyriakarakos, K. G. Arvanitis, and G. Papadakis, "A multi-agent decentralized energy management system based on distributed intelligence for the design and control of autonomous polygeneration microgrids," Energy Conversion and Management, Vol. 103, pp. 166-179 (2015). https://doi.org/10.1016/j.enconman.2015.06.021.

[29] M. La Scala, A. Vaccaro, and A. F. Zobaa, "A goal programming methodology for multiobjective optimization of distributed energy hubs operation," Applied Thermal Engineering, Vol. 71, no. 2, pp. 658666 (2014). https://doi.org/10.1016/j.applthermaleng.2013.10.031.

[30] T. Ma, J. Wu, and L. Hao, "Energy flow modeling and optimal operation analysis of the micro energy grid based on energy hub," Energy Conversion and Management, Vol. 133, pp. 292-306 (2017). https://doi.org/10.1016/j.enconman.2016.12.011.

[31] S Brüggemann. Collaboration and the Semantic Web: Social Networks, Knowledge Networks and Knowledge Resources (IGI Global, New York, 2012).

[32] M. Motevasel, A. R. Seifi, and T. Niknam, "Multi-Objective energy management of CHP (combined heat and power)-based micro-grid", Energy, Vol. 51, pp 123-136 (2013).

https://doi.org/10.1016/j.energy.2012.11.035.

[33] J. Kennedy and R. C. Eberhart, "Particle swarm optimization," in Proceedings of the 1995 IEEE International Conference on Neural Networks, Perth, Australia (IEEE Service Center, Piscataway, NJ, 1995), Vol. 4, pp. 1942-1948. https://doi.org/10.1109/ICNN.1995.488968. 
[34] A. Hussain, S. Y. Arif, M. Aslam, and S. D. A. Shah, "Optimal siting and sizing of tri-generation equipment for developing an autonomous community microgrid considering uncertainties," Sustainable Cities and Society, Vol. 32, pp. 318-330 (2017). https://doi.org/10.1016/j.scs.2017.04.004.

[35] Z. Huang, J. Wang, B. Liu, K. Zeng, J. Yu, and D. Jiang, "Combustion characteristics of a direct-injection engine fueled with natural gas-hydrogen blends under different ignition timings," Fuel, Vol. 86, no. 3, pp. 381-387 (2007). https://doi.org/10.1016/j.fuel.2006.07.007.

[36] D. Y. Goswami and F. Kreith. Energy Conversion (CRC Press Taylor \& Francis Group, Florida, 2007).

[37] S. M. Hakimi, S. M. M. Tafreshi, and A. Kashefi, "Unit sizing of a stand-alone hybrid power system using Particle Swarm Optimization (PSO)," in Proceedings of the 2007 IEEE International Conference on Automation and Logistics, Jinan, China, 18-21 Aug. 2007, pp. 3107-3112. https://doi.org/10.1109/ICAL.2007.4339116.

[38] R. Jabbari-Sabet, S.-M. Moghaddas-Tafreshi, and S.-S. Mirhoseini, "Microgrid operation and management using probabilistic reconfiguration and unit commitment," International Journal of Electrical Power \& Energy Systems, Vol. 75, pp. 328-336 (2016). https://doi.org/10.1016/j.ijepes.2015.09.012.

[39] A. A. Moghaddam, A. Seifi, T. Niknam, and M. R. Alizadeh Pahlavani, "Multi-objective operation management of a renewable MG (micro-grid) with back-up micro-turbine/fuel cell/battery hybrid power source," Energy, Vol. 36, no. 11, pp. 6490-6507 (2011). https://doi.org/10.1016/j.energy.2011.09.017.

[40] L. Zhang and J. Xiang, "The performance of a grid-tied microgrid with hydrogen storage and a hydrogen fuel cell stack," Energy Conversion and Management, Vol. 87, pp. 421-427 (2014). https://doi.org/10.1016/j.enconman.2014.07.045. 